\title{
Disinfectant wipes transfer Clostridioides difficile spores from contaminated surfaces to uncontaminated surfaces during the disinfection process
}

\author{
Carine A. Nkemngong ${ }^{1}$, Gurpreet K. Chaggarr ${ }^{1}$, Xiaobao Li ${ }^{2}$, Peter J. Teska ${ }^{2}$ and Haley F. Oliver ${ }^{1 *}$ (])
}

\begin{abstract}
Background: Pre-wetted disinfectant wipes are increasingly being used in healthcare facilities to help address the risk of healthcare associated infections (HAls). However, HAls are still a major problem in the US with Clostridioides difficile being the most common cause, leading to approximately 12,800 deaths annually in the US. An underexplored risk when using disinfectant wipes is that they may cross-contaminate uncontaminated surfaces during the wiping process. The objective of this study was to determine the cross-contamination risk that pre-wetted disinfectant towelettes may pose when challenged with $C$. difficile spores. We hypothesized that although the tested disinfectant wipes had no sporicidal claims, they will reduce spore loads. We also hypothesized that hydrogen peroxide disinfectant towelettes would present a lower cross-contamination risk than quaternary ammonium products.
\end{abstract}

Methods: We evaluated the risk of cross-contamination when disinfectant wipes are challenged with C. difficile ATCC 43598 spores on Formica surfaces. A disinfectant wipe was used to wipe a Formica sheet inoculated with C. difficile. After the wiping process, we determined $\log _{10}$ CFU on previously uncontaminated pre-determined distances from the inoculation point and on the used wipes.

Results: We found that the disinfectant wipes transferred C. difficile spores from inoculated surfaces to previously uncontaminated surfaces. We also found that wipes physically removed C. difficile spores and that hydrogen peroxide disinfectants were more sporicidal than the quaternary ammonium disinfectants.

Conclusion: Regardless of the product type, all disinfectant wipes had some sporicidal effect but transferred C. difficile spores from contaminated to otherwise previously uncontaminated surfaces. Disinfectant wipes retain C. difficile spores during and after the wiping process.

Keywords: Clostridioides difficile, Cross-contamination, Disinfectants

\section{Background}

Pre-wetted disinfectant wipes are increasingly being used in healthcare facilities to disinfect equipment and environmental surfaces proximal to patients to reduce the

*Correspondence: hfoliver@purdue.edu

1 Department of Food Science, Purdue University, 745 Agriculture Mall Drive, West Lafayette, IN 47907, USA

Full list of author information is available at the end of the article risk of healthcare associated infections (HAIs) [1]. This may play a significant role in reducing the incidence of certain HAIs $[2,3]$. However, despite efforts being made to reduce the incidence of HAIs, one out of 31 patients in the United States (US) acquires one or more HAIs on a daily basis [4]. Among pathogens implicated in the incidence of HAIs, Clostridioides difficile is among the most common in the US [5, 6]. The Center for Disease Control original author(s) and the source, provide a link to the Creative Commons licence, and indicate if changes were made. The images or other third party material in this article are included in the article's Creative Commons licence, unless indicated otherwise in a credit line to the material. If material is not included in the article's Creative Commons licence and your intended use is not permitted by statutory regulation or exceeds the permitted use, you will need to obtain permission directly from the copyright holder. To view a copy of this licence, visit http://creativecommons.org/licenses/by/4.0/. The Creative Commons Public Domain Dedication waiver (http://creativeco mmons.org/publicdomain/zero/1.0/) applies to the data made available in this article, unless otherwise stated in a credit line to the data. 
and Prevention (CDC) estimated that in 2017 there were approximately 223,900 hospitalized patients with $C$. difficile infections in the US with at least 12,800 deaths [6]. In acute care facilities, $C$. difficile infections result in approximately $\$ 4.8$ billion in extra healthcare costs [5] due to prolonged hospital stays and readmissions $[5,7]$.

The contamination of environmental surfaces in healthcare facilities may account for up to $20 \%$ of HAIs [8]. Specifically, hard non-porous environmental surfaces such as bed rails [9-11] and bedside tables [9] may harbor $C$. difficile spores and contribute to transmission resulting in HAIs in healthcare facilities [12]. The eradication of C. difficile from environmental surfaces could be particularly challenging as spores can persist on environmental surfaces for months $[8,13]$. Specifically, the persistence of $C$. difficile spores on environmental surfaces has been associated with the use of non-sporicidal cleaning agents such as quaternary ammonium compounds, which may increase $C$. difficile sporulation rates [14]. Consequently, the use of disinfectant wipes with $C$. difficile sporicidal claims have been recommended to reduce the incidence of HAIs [15], as wipes have been suggested to increase compliance with standard cleaning and disinfection protocols [16].

In the US, healthcare facilities commonly use visual evaluations to determine "contamination levels" on hard non-porous surfaces prior to disinfection [17]. Consequently, irrespective of spore or vegetative state on surfaces, broad-spectrum antimicrobial wipes, such as those loaded with quaternary ammonium compounds, are relied on for routine disinfection practices [18-20]. However, pre-wetted disinfectant wipes may pose the risk of cross-contaminating "clean" surfaces during the wiping process [21]. This may be product-dependent as Siani et al. demonstrated that sodium hypochlorite wipes are more sporicidal against $C$. difficile than quaternary ammonium compounds (QAC) [1]. Other differences in the bactericidal efficacy of disinfectant active ingredients have been reported by Lineback et al. who demonstrated that hydrogen peroxides and sodium hypochlorites were more bactericidal against bacterial biofilms than QAC [22]. In addition, the Environmental Protection Agency (EPA) has no recommendation on the maximum surface area that could be disinfected with a towelette in order to optimize bactericidal efficacy, while minimizing the risk of cross-contaminating low risk surfaces.

The risk of pathogen transmission by the hands of healthcare workers and patients has been widely investigated [23-25]. However, less work [17, 26] has been done to determine the risk of cross-contamination by disinfectant wipes using real world techniques in vitro as standard testing for the registration of towelette products rarely mandate the simulation of real world wiping scenarios [3]. The objective of this study was to determine the cross-contamination risk that disinfectant towelettes with no sporicidal claims may pose when challenged with $C$. difficile spores. We hypothesized that although the tested disinfectant wipes have no sporicidal claims, they will reduce $C$. difficile spore loads, but cross-contamination may still occur. On a related note, we hypothesized that towelettes with sporicidal claims will present a lower cross-contamination risk than wipes without sporicidal claims. We also hypothesized that compared to quaternary ammonium products, hydrogen peroxide disinfectant towelettes will present a lower risk of cross-contaminating low risk surfaces after wiping down an area inoculated with $C$. difficile spores.

\section{Methods}

\section{Disinfectants and bacterial strain used in this study}

This study investigated the risk of cross-contamination of seven disinfectant towelette products; six with nonsporicidal claims and one product with sporicidal claims (Table 1). Ready-to-use wipes containing $1.312 \%$ sodium hypochlorite with an EPA registered sporicidal claim were used as a control. C. difficile spores ATCC 43598 were produced following EPA MLB SOP-MB-28 [27] and used to study the risk of cross-contamination by disinfectant wipes following a modified version of EPA MLB SOP-MB-31 [28].

\section{Test surface sterilization, inoculation and disinfection}

A two-meter square area of Formica sheeting was marked into different lengths and labeled as follows: inoculation zone (i-zone), $0.5 \mathrm{~m}^{2}, 1 \mathrm{~m}^{2}, 1.5 \mathrm{~m}^{2}$ and $2 \mathrm{~m}^{2}$ (Fig. 1). For the i-zone and for every $0.5 \mathrm{~m}^{2}$ area, a $10 \mathrm{~cm} \times 10 \mathrm{~cm}$ $\left(100 \mathrm{~cm}^{2}\right)$ area was marked in the center of the defined lengths to recover spores from the surface. The entire Formica surface was sterilized by a three-step process. Progressively, the surface was cleaned with $7.0 \%$ hydrogen peroxide, $10 \%$ bleach and $70 \%$ ethanol. Following each of the first two disinfection processes, three rinses each with $250 \mathrm{ml}$ of sterile distilled water was used to rinse the surface. This was followed by a final application of $70 \%$ ethanol. The Formica sheet was left to air-dry on a clean laboratory bench.

The $C$. difficile spore inoculum was prepared following EPA MLB SOP-MB-31 [28] and used to test the risk of cross-contamination by disinfectant wipes from the "i-zone" to other portions of the Formica sheet. A final spore suspension of $500 \mu \mathrm{L}$ was prepared with a soil load composed of $25 \mu \mathrm{L} 0.05 \%$ bovine serum albumin (BSA; Fisher bioreagents, Ottawa, Canada), $35 \mu \mathrm{L}$ 0.05\% yeast extract (ACROS Organics, New Jersey, US), 100 $\mu \mathrm{L}$ 0.004\% mucin stock (Abnova, Walnut, USA), and $340 \mu \mathrm{L} \mathrm{C}$. difficile spores (prepared following EPA MLB 
Table 1 Active ingredients and contact times for disinfectant towelettes tested in this study

\begin{tabular}{|c|c|c|c|c|}
\hline $\begin{array}{l}\text { Disinfectant } \\
\text { product }^{\text {a }}\end{array}$ & Disinfectant active ingredient(s) $^{c}$ & Dilution at use & Active level at use $e^{e}$ & $\begin{array}{l}\text { Label } \\
\text { contact time } \\
\text { (mins) }^{f}\end{array}$ \\
\hline $\mathrm{SH}^{\mathrm{b}}$ & $1.312 \%$ sodium hypochlorite & RTU ${ }^{d}$ & $1.25 \%$ & 4 \\
\hline HP1 & $1.4 \%$ hydrogen peroxide & RTU & $1.4 \%$ & 1 \\
\hline HP2 & $0.5 \%$ hydrogen peroxide & RTU & $0.5 \%$ & 1 \\
\hline HP3 & $0.5 \%$ hydrogen peroxide & RTU & $0.5 \%$ & 1 \\
\hline QA1 & $\begin{array}{l}0.25 \% \text { n-alkyl }\left(68 \% C_{12}, 32 \% C_{14}\right) \text { dimethylethylbenzyl } \\
\text { ammonium chloride } \\
0.25 \% \text { n-alkyl }\left(60 \% C_{14}, 30 \% C_{16,}, 5 \%\right. \\
\left.C_{12}, 5 \% C_{18}\right) \text { dimethyl benzyl ammonium chloride } \\
55 \% \text { isopropanol }\end{array}$ & RTU & $0.5 \%{ }^{9}+55 \%$ & 2 \\
\hline QA2 & $\begin{array}{l}0.76 \% \text { didecyldimethyl ammonium chloride } \\
15 \% \text { isopropanol } \\
7.50 \% \text { ethanol }\end{array}$ & RTU & $0.76 \%^{9}+22.5 \%$ & 1 \\
\hline QA3 & $\begin{array}{l}0.233 \% \text { disobutylphenolxyethoxyethyl dimethyl benzyl } \\
\text { ammonium chloride } \\
14.3 \% \text { isopropanol }\end{array}$ & RTU & $0.233 \%^{9}+14.3 \%$ & 2 \\
\hline
\end{tabular}

\footnotetext{
a Abbreviated naming scheme for commercially available EPA registered disinfectants used in this study

b Control disinfectant with C. difficile claim

c Active ingredients concentration

d Ready-to-use

e Active ingredient concentration after dilution

f Defined label contact time

g Total quaternary ammonium plus alcohol content
}

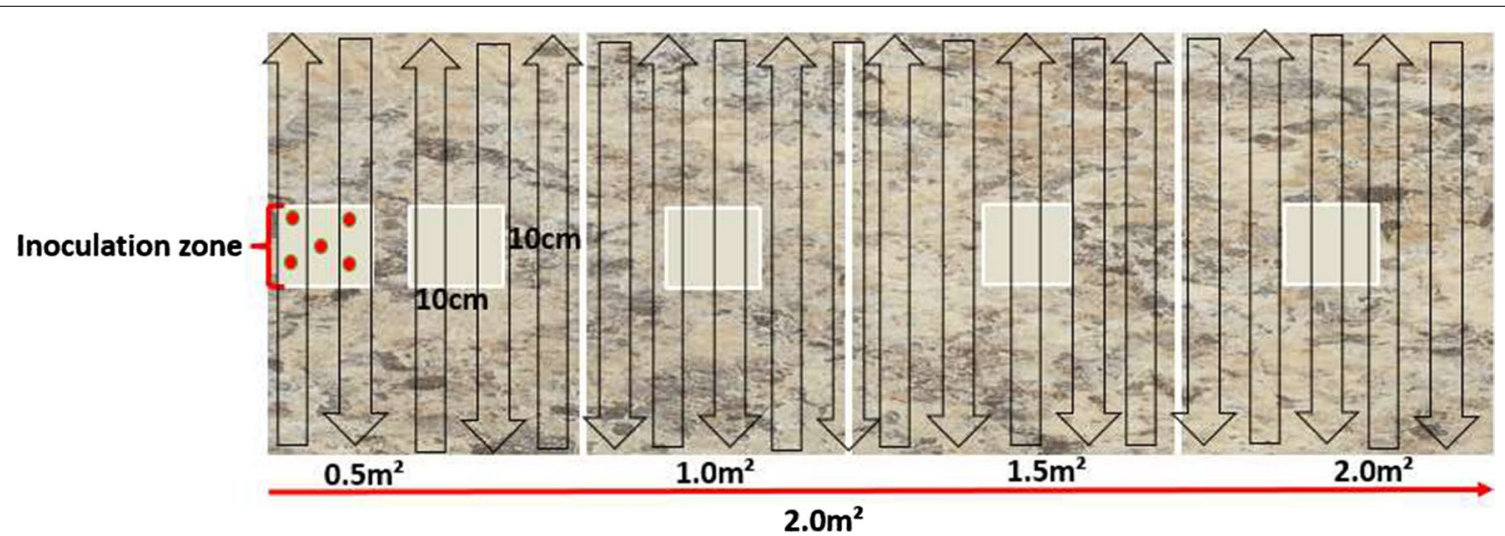

Fig. 1 Schematic diagram of the Formica surface used for wipe testing. Two meters of Formica were delineated into $0.5 \mathrm{~m}^{2}$ sections. $5.0 \times 10^{8}$ $\log _{10}$ CFU C. difficile spores were spotted onto the inoculation zone (i-zone) as represented by red dots. The entire surface was wiped in an up and down motion across the entire surface as indicated by black outlined arrows from left to right. $10 \mathrm{~cm} \times 10 \mathrm{~cm}\left(100 \mathrm{~cm}^{2}\right)$ sampling zones (light gray squares) were sampled to recover potentially cross-contaminated spores

SOP MB-28; stored at $\left.-20 \pm 5{ }^{\circ} \mathrm{C}\right)$. After sterilizing the entire two-meter square area, a marked $10 \mathrm{~cm} \times 10 \mathrm{~cm}$ $\left(100 \mathrm{~cm}^{2}\right)$ area in the $\mathrm{i}$-zone was inoculated with five $10 \mu \mathrm{l}$ aliquots of the $C$. difficile spore suspension (approximately $5.0 \times 10^{8}$ colony forming units per $\mathrm{ml}$ ) following EPA MLB SOP-MB-28 [29]. The first two towelettes from each disinfectant were discarded and the third used for testing to ensure enough disinfectant liquid load on the towelettes. This was used to wipe the entire two-meter square Formica sheet from the i-zone of the Formica to the two-meter mark of the Formica. The surface was wiped in a continuous up and down movement (Fig. 1). This was repeated for the entire surface area of the Formica sheet starting with the i-zone. The designated surfaces were left at room temperature for the disinfectants' defined label contact times (Table 1). At the full contact 
time, swab samples of $100 \mathrm{~cm}^{2}$ were collected from every $0.5 \mathrm{~m}^{2}$ starting with the inoculation area using PUR-Blue Swabs (World BioProducts, Libertyville, IL; containing $10 \mathrm{~mL}$ sterile HiCap neutralizing buffer). The swab samplers were each vortexed for $30 \mathrm{~s}$ to release the bacterial spores from the sponge into the solution. The used wipes were placed in a sterile stomacher bag (Whirl-Pak, Nasco, Fort Atkinson, WI) containing $50 \mathrm{~mL}$ of $0.52 \%$ neutralizing buffer (BD Difco, Becton, Dickinson and Company, MD, USA), shaken for five min at $230 \mathrm{rpm}$ using a stomacher to detect viable $C$. difficile spores on the towelette. Ten ml neutralizing buffer from the PURBlue swabs and the sterile stomacher bags were vacuum-filtered onto a membrane filter $(0.2 \mu \mathrm{m}$ pore size, $47 \mathrm{~mm}$ grid, individual sterile pack; Pall Corporation, Port Washington, NY) following EPA MLB SOP-MB-31 [28]. The membrane filters were aseptically transferred to pre-reduced brain-heart infusion agar with yeast extract, horse blood and sodium taurocholate plates (BHIY-HT; Anaerobe Systems, Morgan Hill, CA) and incubated under anaerobic conditions at $36 \pm 1{ }^{\circ} \mathrm{C}$ for $120 \pm 4 \mathrm{~h}$ before colonies characteristic of $C$. difficile spores as stated in EPA-MLB SOP-MB-31 were counted. Anaerobic conditions were achieved using an anaerobic jar (BD BBL GasPak, Becton, Dickinson and Company, Franklin Lakes, $\mathrm{NJ}$ ) and $\mathrm{CO}_{2}$ gas generating packs (BD GasPak, Becton, Dickinson and Company, MD, USA). Five biological replicates were conducted for each of the disinfectant products tested and one technical replicate performed for each biological replicate per surface area tested.

\section{Statistical analysis}

C. difficile spores were recovered from five test zones of a two-meter square Formica sheet and from used disinfectant wipes; counts were $\log _{10}$-transformed. Average $\log _{10}$ CFU were calculated for wipes and defined sampled surfaces to test for statistically significant differences among eight disinfectant products. Specifically, we tested for differences among sampled surfaces by analyzing $\log _{10}$ $\mathrm{CFU} / 100 \mathrm{~cm}^{2}$ counts recovered after disinfection. We also analyzed $\log _{10} \mathrm{CFU} /$ wipe used to test for the risk of cross-contamination from the i-zone to low risk surfaces. The least squares method of the Proc Glimmix test was used to fit liner models $(n=42, \alpha=0.05)$ and to test for interactions between disinfectant $\log _{10} \mathrm{CFU} / 100 \mathrm{~cm}^{2}$ and the surface area sampled. Surface area wiped and product type were treated as variables with continuous effects (repeated measures in Proc Glimmix). Tukey adjustments were used to test for significant differences in mean $\log _{10}$ CFU among disinfectant products. The same procedure was also used to test for significant differences among surfaces treated with the same disinfectant wipe.

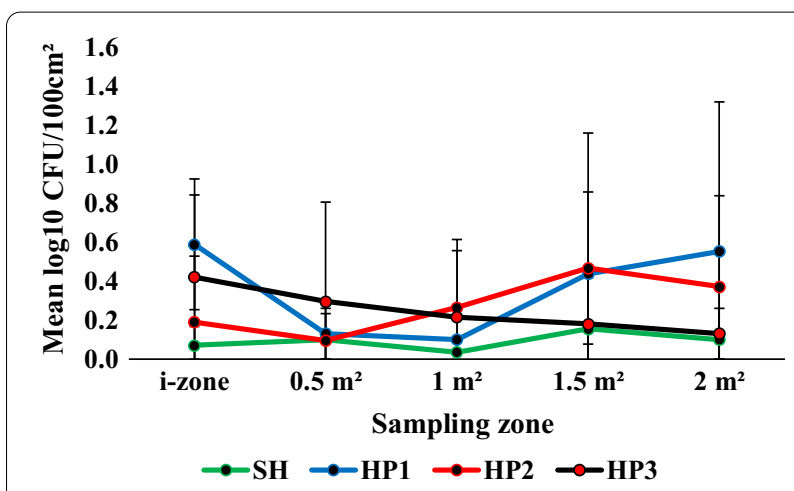

Fig. 2 Mean $\log _{10} \mathrm{CFU} / 100 \mathrm{~cm}^{2}$ remaining on sampled portions of the Formica sheet post disinfection with $\mathrm{SH}$ or hydrogen peroxide disinfectant wipes

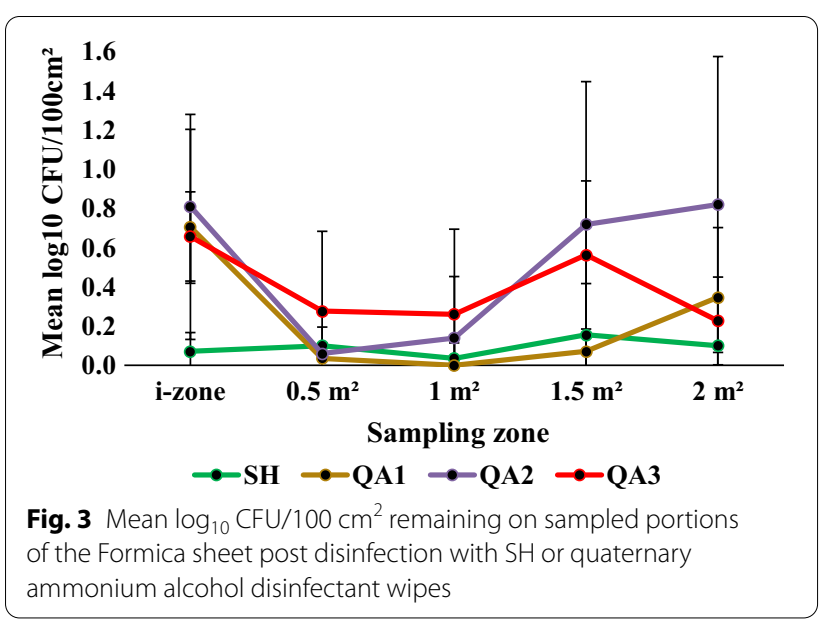

All statistical tests were conducted using SAS version 9.4 (SAS institute, Cary, NC).

\section{Results}

Disinfectant wipes transfer varied levels of $C$. difficile spores to low risk (not previously contaminated) hard non-porous surfaces

Regardless of disinfectant product, both the sporicidal or non-sporicidal disinfectant wipes cross-contaminated low risk or otherwise previously uncontaminated surfaces from the i-zone (Figs. 2, 3). On average, $0.49 \pm 0.27 \log _{10}$ $\mathrm{CFU} / 100 \mathrm{~cm}^{2}$ was recovered from the i-zone after the wiping process. Overall, a disinfectant wipe transferred a mean of $0.13 \pm 0.12$ and $0.34 \pm 0.27 \log _{10} C F U / 100 \mathrm{~cm}^{2}$ from the i-zone to the $0.5 \mathrm{~m}^{2}$ and $2.0 \mathrm{~m}^{2}$ risk surfaces respectively. Similarly, each wipe transferred on average, $0.13 \pm 0.11$ and $0.36 \pm 0.25 \log _{10} \mathrm{CFU} / 100 \mathrm{~cm}^{2}$ from the i-zone to the $1 \mathrm{~m}^{2}$ and $1.5 \mathrm{~m}^{2}$ surfaces respectively.

The surface area wiped was statistically significant $(P<0.05)$. On average, the $\log _{10} \mathrm{CFU} / 100 \mathrm{~cm}^{2}$ transferred 
to $0.5 \mathrm{~m}^{2}$ and $1 \mathrm{~m}^{2}$ surfaces from the i-zone were significantly lower compared to the $\log _{10} \mathrm{CFU} / 100 \mathrm{~cm}^{2}$ recovered from the i-zone post disinfection $(P<0.05)$. However, there were no statistically significant differences among the $C$. difficile spore $\log _{10} C F U / 100 \mathrm{~cm}^{2}$ transferred to the $1.5 \mathrm{~m}^{2}$ and $2.0 \mathrm{~m}^{2}$ surfaces and the $\log _{10}$ $\mathrm{CFU} / 100 \mathrm{~cm}^{2}$ detected from the i-zone after the wiping process $(P \geq 0.05)$. There were also no statistically significant differences among the mean $\log _{10} C F U / 100 \mathrm{~cm}^{2}$ detected from the $0.5 \mathrm{~m}^{2}, 1 \mathrm{~m}^{2}, 1.5 \mathrm{~m}^{2}$, and $2 \mathrm{~m}^{2}$ surfaces post disinfection $(P \geq 0.05)$.

Regarding cross-contaminating otherwise low risk surfaces $\left(0.5-2.0 \mathrm{~m}^{2}\right)$, the product type was statistically relevant $(P<0.05)$. From the $\mathrm{i}$-zone, the mean $\log _{10}$ $\mathrm{CFU} / 100 \mathrm{~cm}^{2}$ transferred to the $0.5-2.0 \mathrm{~m}^{2}$ zones ranged from $0.04 \pm 0.05(\mathrm{SH}), \quad 0.11 \pm 0.16(\mathrm{QA} 1), \quad 0.21 \pm 0.07$ (HP3), $0.28 \pm 0.26$ (HP1), $0.30 \pm 0.16$ (HP2), $0.33 \pm 0.16$ (QA3) and $0.43 \pm 0.39$ (QA2). QA2 and QA3 wipes transferred at significantly higher $\log _{10} \mathrm{CFU} / 100 \mathrm{~cm}^{2}$ from the i-zone to the $0.5 \mathrm{~m}^{2}, 1 \mathrm{~m}^{2}, 1.5 \mathrm{~m}^{2}$, and $2 \mathrm{~m}^{2}$ surfaces compared to the control, SH $(P<0.05$; Fig. 3; Additional file 1). However, QA1 transferred significantly lower $\log _{10}$ $\mathrm{CFU} / 100 \mathrm{~cm}^{2}$ from the i-zone to the $0.5-2.0 \mathrm{~m}^{2}$ areas than QA2 and QA3 $(P<0.05$; Fig. 3; Additional file 1). There were no statistically significant differences in the cross-contamination levels (mean $\log _{10} \mathrm{CFU} / 100 \mathrm{~cm}^{2}$ ) among SH, HP1, HP2, HP3, and QA1 ( $P \geq 0.05$; Figs. 2, 3; Additional file 1).

\section{High levels of $C$. difficile spores were recovered from disinfectant towelettes after use}

Overall, all disinfectant wipes retained $C$. difficile spores after surface disinfection (Fig. 3); there were statistically significant differences among products $(P<0.05)$. The $\log _{10}$ CFU/wipe ranged from $0.70 \pm 0.00$ (minimum detection level) for $\mathrm{SH}$ to $2.43 \pm 0.72$ for QA2 after use (Fig. 3). The mean $\log 10 \mathrm{CFU} /$ wipe for the quaternary alcohol products were $1.95 \pm 0.12,2.43 \pm 0.72$ and $2.43 \pm 0.52$ for QA1, QA2 and QA3, respectively. After the wiping process, control wipes $(\mathrm{SH})$ were significantly less contaminated than towelettes of QA1, QA2 and QA3 $(P<0.05$; Fig. 4). Comparing QA products only, there were no statistically significant differences among the $\log _{10} C F U /$ wipe recovered on wipes of QA1, QA2 and QA3 post disinfection $(P \geq 0.05$; Fig. 3$)$. Similarly, there were no significant differences among the $\log _{10}$ spore counts on HP1, HP2 and HP3 towelettes after the wiping process as the average $\log 10 \mathrm{CFU} /$ wipe were $1.38 \pm 0.45$, $1.17 \pm 0.31$ and $0.79 \pm 0.14$ for HP1, HP2 and HP3, respectively ( $P \geq 0.05$; Fig. 4$)$. Also, there were no statistically significant differences between $\log _{10}$ CFU counts from $\mathrm{SH}$ and HP1, and HP2 and HP3 wipes $(\mathbf{P} \geq 0.05$; Fig. 4).

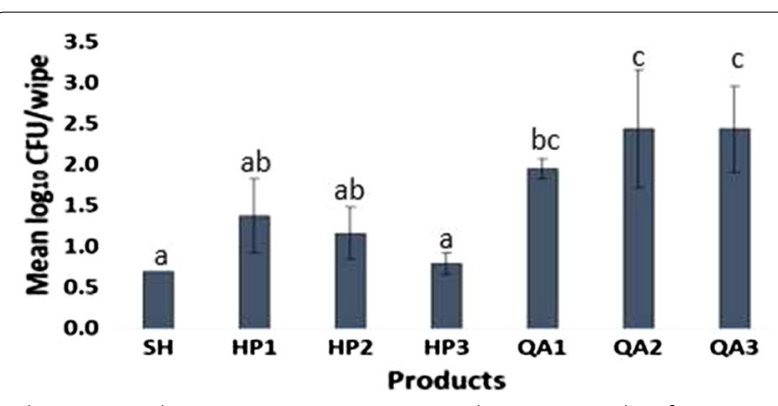

Fig. 4 Mean $\log _{10}$ CFU remaining on used wipes post disinfection with $\mathrm{SH}$, hydrogen peroxide or quaternary ammonium alcohol disinfectant wipes. Bars with the same Turkey letter are statistically similar

In comparing the $\log _{10} \mathrm{CFU} /$ wipe of QA and HP products, there were no statistically significant differences among $\log _{10}$ CFU/wipe recovered from HP1, HP2 and QA1 wipes ( $P \geq 0.05$; Fig. 4$)$. However, significantly lower contamination levels were observed on used HP1, HP2, and HP3 wipes compared to QA2 and QA3 $(\mathbf{P}<0.05$; Fig. 4).

\section{The sporicidal efficacy of disinfectant towelettes varies by product type and surface area}

The product type was statistically significant $(P<0.05)$. The mean $\log _{10}$ CFU/100 $\mathrm{cm}^{2}$ recovered from the i-zone $-2.0 \mathrm{~m}^{2}$ post disinfection ranged from $0.05 \pm 0.04$ for $\mathrm{SH}$ to $0.51 \pm 0.38$ for QA2. For the QA products, the mean $\log _{10} \mathrm{CFU} / 100 \mathrm{~cm}^{2}$ (i-zone-2.0 $\mathrm{m}^{2}$ ) were $0.23 \pm 0.30$ (QA1), $0.51 \pm 0.38$ (QA2) and $0.40 \pm 0.20$ (QA3). For HP products, the average $\log _{10} \mathrm{CFU} / 100 \mathrm{~cm}^{2}$ recovered from the i-zone $-2.0 \mathrm{~m}^{2}$ areas were $0.34 \pm 0.26$ (HP1), $0.28 \pm 0.15$ (HP2) and $0.25 \pm 0.11$ (HP3). SH was significantly more sporicidal than QA2 and QA3 $(P<0.05)$ as on average, lower $\log _{10} C F U / 100 \mathrm{~cm}^{2}$ were recovered from the i-zone and subsequent surfaces $\left(0.5 \mathrm{~m}^{2}, 1 \mathrm{~m}^{2}, 1.5 \mathrm{~m}^{2}\right.$, and $\left.2 \mathrm{~m}^{2}\right)$ (Fig. 3; Additional file 1). However, there were no statistically significant differences among the sporicidal efficacies of SH, HP1, HP2, HP3 (Fig. 2; Additional file 1) and QA1 ( $P \geq 0.05$; Fig. 3, Additional file 1) as the mean $\log _{10} C F U / 100 \mathrm{~cm}^{2}$ across the tested surfaces were very similar.

Surface area wiped was statistically significant $(P<0.05)$ and overall, the sporicidal efficacy of disinfectant wipes decreased with an increase in the surface area wiped from 0.5 to $2 \mathrm{~m}^{2}$ (Figs. 2, 3; Additional file 1). Compared to the $1.5 \mathrm{~m}^{2}$ and $2 \mathrm{~m}^{2}$ areas, disinfectant towelettes were statistically more sporicidal when used on the $0.5 \mathrm{~m}^{2}$ and $1 \mathrm{~m}^{2}$ surface areas $(P<0.05)$. This was the case as $\log _{10}$ $\mathrm{CFU} / 100 \mathrm{~cm}^{2}$ from the $0.5 \mathrm{~m}^{2}$ and $1 \mathrm{~m}^{2}$ surfaces were significantly lower relative to the i-zone $(P<0.05$; Figs. 2 , 
3). Overall, there were no statistically significant differences in the sporicidal efficacy of disinfectant towelettes when the $\log _{10} \mathrm{CFU} / 100 \mathrm{~cm}^{2}$ from the i-zone, $1.5 \mathrm{~m}^{2}$ and $2 \mathrm{~m}^{2}$ areas were compared $(P \geq 0.05)$. Similarly, regardless of the active ingredient class, and without comparison to the i-zone, there were no statistically significant differences in the sporicidal efficacies recorded within the $0.5 \mathrm{~m}^{2}, 1 \mathrm{~m}^{2}, 1.5 \mathrm{~m}^{2}$ and $2 \mathrm{~m}^{2}$ surface areas $(P \geq 0.05$, Figs. 2, 3; Additional file 1).

\section{Discussion}

In this study, we determined the cross-contamination risk that disinfectant wipes may pose during and after the wiping process. We established that during the wiping process, disinfectant wipes transfer $C$. difficile spores from a contaminated surface (i-zone) to otherwise uncontaminated surfaces during the disinfection process. We also found that among all the used disinfectant wipes tested in this study, viable $C$. difficile spores were detected on the wipes post disinfection. Overall, we found that after the wiping process, the $\log _{10} \mathrm{CFU} / 100 \mathrm{~cm}^{2}$ detected from the $0.5 \mathrm{~m}^{2}$ and $1 \mathrm{~m}^{2}$ surfaces were significantly lower compared to those recovered from the i-zone. However, there were no significant differences among the $\log _{10}$ CFU/ $100 \mathrm{~cm}^{2}$ transferred to the $1.5 \mathrm{~m}^{2}$ and $2.0 \mathrm{~m}^{2}$ surfaces and the $\log _{10} \mathrm{CFU} / 100 \mathrm{~cm}^{2}$ recovered from the i-zone post-disinfection.

\section{Disinfectant wipes cross-contaminate hard non-porous surfaces}

Cross-contamination is described by the CDC as the transfer of bacteria by contact from one surface to another [30]. Disinfectant wipes were the transfer "agents" between the surface inoculated with $C$. difficile spores and non-contaminated surfaces. In a similar study, Lopez et al. found that Bacillus thuringiensis spores inoculated on inanimate surfaces were transferred from wipedisinfected fomites to fingers [31]. More recently, Becker et al. demonstrated that disinfectant wipes loaded with propanol or quaternary ammonium compounds (QAC) transferred viruses from a $25 \mathrm{~cm}^{2}$ inoculated surface onto three other surfaces of the same size in the process of using the wipes [26].

Compared to the i-zone, the $\log _{10} \mathrm{CFU} / 100 \mathrm{~cm}^{2}$ from the $0.5 \mathrm{~m}^{2}$ and $1 \mathrm{~m}^{2}$ low risk surfaces were significantly lower than the $\log _{10} \mathrm{CFU} / 100 \mathrm{~cm}^{2}$ of the i-zone post disinfection. This could be explained by the observation that more disinfectant liquid was released from the wipe onto the $0.5 \mathrm{~m}^{2}$ and $1 \mathrm{~m}^{2}$ areas compared to the $1.5 \mathrm{~m}^{2}$ and $2 \mathrm{~m}^{2}$ areas. This was evident as the $0.5 \mathrm{~m}^{2}$ and $1 \mathrm{~m}^{2}$ surfaces were visibly wet after the wiping process. While the i-zone was also visibly wet, it is likely that the amount of liquid disinfectant dispensed from products without sporicidal claims were insufficient to result in any significant kill. This may be the case as within the i-zone, wipes were challenged with approximately $5.0 \times 10^{8} \log _{10} \mathrm{CFU}$, and lower $\log _{10}$ $\mathrm{CFU}$ thereafter as it is likely that disinfectant wipes did not physically pick up all $5.0 \times 10^{8} \log _{10}$ CFU from the i-zone. Moreover, West et al. suggested that the high amount of disinfectant liquid released from a quaternary ammonium disinfectant wipe for example may cause a "gliding" effect resulting in a reduction in the physical removal of microorganisms by wipes [32]. In a previous study by our group [32], we found that the percent of liquid released per $0.1 \mathrm{~m}^{2}$ of a Formica surface significantly decreased as the surface area wiped increased. We found that overall, the $\log _{10}$ CFU/100 $\mathrm{cm}^{2}$ recovered from the $1.5 \mathrm{~m}^{2}$ and $2.0 \mathrm{~m}^{2}$ areas were comparable to that recovered from the i-zone post disinfection. This suggests that in the disinfection of larger surfaces, cross-contamination may continuously increase to levels that are comparable with the "residual" spores from the contamination source post disinfection.

Regardless of the product type, and without comparison to the i-zone, there were no significant differences in the $\log _{10} \mathrm{CFU} / 100 \mathrm{~cm}^{2}$ of spores detected from $0.5 \mathrm{~m}^{2}$, $1.0 \mathrm{~m}^{2}, 1.5 \mathrm{~m}^{2}$ and $2.0 \mathrm{~m}^{2}$ surface areas. In a similar study, Becker et al. did not find significant differences in the titer of viruses detected from three $25 \mathrm{~cm}^{2}$ uncontaminated surfaces after wiping them with a QAC disinfectant wipe previously used on a contaminated surface [26]. The reported risk of cross-contamination by $C$. difficile spores is particularly relevant in healthcare settings as $C$. difficile infections have been associated with contaminated environmental surfaces and are a leading cause of HAIs in the US [6, 33-35].

Among disinfectants with the same active ingredients a (e.g. QA products) there were significant differences in the cross-contamination risk as QA1 presented a lower cross-contamination risk than QA2 and QA3. It is possible that the higher alcohol content of QA1 (55\%) compared to $22.5 \%$ for QA2 and $14.3 \%$ for QA3 made it more sporicidal (Table 1). This could be further supported as the spore load on QA1 wipes after use were similar to those of products with active ingredient classes that are generally sporicidal in nature (HP1 and HP2) [36]. There were no statistically significant differences among the cross-contamination risk of HP products and $\mathrm{SH}$. This suggest that although these products did not carry sporicidal claims, the products exhibited significant sporicidal action. This could be explained by the fact that hydrogen peroxides are generally a class of active ingredients used for sterilization purposes [36] owing to their ability to inactivate spores. 


\section{Used disinfectant wipes are potential cross-contamination} agents after use

Although used disinfectant wipes are typically considered standard medical waste [37], we found that used disinfectant wipes may retain high numbers of $C$. difficile spores after use. This demonstrates a "mechanical" spore removal mechanism from contaminated surfaces during the wiping process. This finding is similar to those of Gonzales et al. who reported a physical removal of Clostridium sporogenes and Bacillus atrophaeus spores by antimicrobial wipes during the wiping process [38]. Kenters et al. also reported a similar mechanical removal effect by wipes challenged with $C$. difficile spores [39]. We observed that after wiping down the Formica sheet, all the used disinfectant towelettes were dry to the feel. This suggests that after use, the residual disinfectant liquid on the wipe may be insufficient to kill the spores picked up on the cloth within the product's label-defined contact time. The ability for disinfectant wipes to retain spores after use may present a considerable cross-contamination risk especially if the same wipe is used on multiple surfaces or pieces of equipment. Siani et al. reported that disinfectant towelettes with no sporicidal claims that harbored $C$. difficile spores could eventually serve as crosscontamination agents [1].

The wipe design and substrate may also play a significant role in the level of organisms removed by the wipe [40]. Although the specific effects of the wipe materials were not evaluated in this study, differences in the levels of spores retained on the wipe could be associated with the wipe material type and with the amount of disinfectant liquid loaded on the wipe. Some wipe material types may hold more disinfectant liquid, which may be helpful in disinfection. We observed that wipes that had a rough feel probably due to their low cotton content (mostly the QA wipes) retained higher spore loads. In a 2012 study, Masuku et al. reported that the kind of material the wipe was made of, significantly impacted disinfection levels [41].

\section{Hydrogen peroxide-based wipes are more sporicidal than wipes with QACs}

All hydrogen peroxide-based disinfectants tested in this study were more sporicidal than most $(2 / 3)$ of the QAC disinfectant wipes tested. The sporicidal activity of hydrogen peroxides has been associated with their ability to produce free hydroxyl radicals after binding to deoxyribonucleic acids (DNA) [42]. These hydroxyl free radicals damage DNA and cell membrane lipids [42]. Although the tested disinfectants, with the exception of $\mathrm{SH}$, had no sporicidal claims, we found that all the tested disinfectants reduced spore loads. This is likely a joint effect of physical spore removal by the wipe substrate and spore inactivation by the disinfectants $[3,39,43]$. Specifically, Rutala et al. reported that disinfectant wipes with no sporicidal claims had sporicidal effects, and the wipes could physically remove more than 2.9 logs of $C$. difficile spores from inoculated surfaces [43]. Our findings were similar to that of Rutala et al. [43] as the sporicidal efficacy of disinfectant wipes with non-sporicidal claims (HP1, HP2, HP3 and QA1) were comparable to that of $\mathrm{SH}$ with a sporicidal claim.

The US EPA requirements for obtaining a disinfectant label claim for $C$. difficile require a minimum of a six $\log _{10}$ reduction [44]. But in our study, we found no statistical difference in disinfectant performance between all of the hydrogen peroxide wipes without a $C$. difficile sporicidal label claim and the sodium hypochlorite-based product with a $C$. difficile sporicidal label claim. This suggest that the benefits in efficacy in passing the EPA method may not translate to actual differences in efficacy in real world use, as simulated in this study. Thus, there may be no actual clinical benefit from using a sporicidal disinfectant wipe in reducing patient risk of $C$. difficile infection versus using a hydrogen peroxide (non-sporicidal) disinfectant wipe. This needs further study.

We acknowledge that our study is limited as we did not investigate the effect the different wipe materials could have on the risk of cross-contamination. We also did not study the impact of a prolonged contact time on the inactivation of spores retained by used disinfectant wipes. It may also be of interest to investigate the cross-contamination risk presented by traditional "bucket and wipe" disinfection methods in comparison to the use of readyto-use disinfectant wipes; these study limitations warrant further study.

\section{Conclusion}

Overall, disinfectant wipes may transfer $C$. difficile spores from contaminated to uncontaminated surfaces and retain high spore loads after the disinfection process, but the rate at which this occurs varies by product and likely is affected by the disinfectant liquid load, chemistry, and wiping material. We determined that non-sporicidal wipes reduce spore load, but the need to conduct similar studies using prevalent HAIs pathogens as Staphylococcus aureus and Pseudomonas aeruginosa remains. We definitively established that when disinfectant wipes are used on large surface areas, they may present a considerable cross-contamination risk, which could put patients at greater risk of HAIs. 


\section{Supplementary information}

Supplementary information accompanies this paper at https://doi. org/10.1186/s13756-020-00844-0.

Additional file 1. Supplemental Data outlines the mean $\log _{10}$ CFU/100 $\mathrm{cm}^{2}$ obtained from the i-zone, $0.5 \mathrm{~m}^{2}, 1.0 \mathrm{~m}^{2}, 1.5 \mathrm{~m}^{2}$ and $2.0 \mathrm{~m}^{2}$ surface areas for all evaluated products.

\section{Abbreviations}

ATCC: American type culture collection; BHIY-HT: Brain-heart infusion agar with yeast extract, horse blood and sodium taurocholate; CDC: Center for Disease Control; CFU: Colony forming unit; DNA: Deoxyribonucleic acids; EPA: Environmental Protection Agency; HAls: Healthcare-associated infections; TSB: Tryptic soy broth; QAC: Quaternary ammonium compounds.

\section{Acknowledgements}

Dr. Oliver is supported by the USDA National Institute of Food and Agriculture Hatch project 2016-67017-24459.

\section{Authors' contributions}

CAN and GKC performed trials to develop the model, analysed and interpreted the data generated, and wrote the manuscript. XL provided industry experience, designed elements of the experimental protocol, and was a contributor in writing and editing the manuscript. PT also provided industry experience and was a contributor in writing and editing the manuscript. HFO served as the principal investigator for the study and was a contributor in writing and editing the manuscript. All authors read and approved the final manuscript.

\section{Funding}

This work was supported by Diversey Inc., Charlotte, NC, USA.

\section{Availability of data and materials}

All quantitative data generated or analysed during this study are included in this published article.

\section{Ethics approval and consent to participate}

Not applicable.

\section{Consent for publication}

Not applicable.

\section{Competing interests}

HFO, CAN, GKC, report grants from Diversey, Inc. during the conduct of the study. PT and XL report grants from Diversey, Inc. during the conduct of the study; personal fees from Diversey, Inc., outside the submitted work.

\section{Author details}

1 Department of Food Science, Purdue University, 745 Agriculture Mall Drive, West Lafayette, IN 47907, USA. ${ }^{2}$ Diversey Inc., Charlotte, NC 28273, USA.

Received: 28 February 2020 Accepted: 27 October 2020

Published online: 04 November 2020

\section{References}

1. Siani H, Cooper C, Maillard JY. Efficacy of "sporicidal" wipes against Clostridium difficile. Am J Infect Control. 2011;39:212-8.

2. Coia JE, Duckworth GJ, Edwards DI, Farrington M, Fry C, Humphreys H, Mallaghan C, Tucker DR. Guidelines for the control and prevention of meticillin-resistant Staphylococcus aureus (MRSA) in healthcare facilities. J Hosp Infect. 2006;63:1-44.

3. Sattar SA, Bradley C, Kibbee R, Wesgate R, Wilkinson MA, Sharpe T, Maillard JY. Disinfectant wipes are appropriate to control microbial bioburden from surfaces: use of a new ASTM standard test protocol to demonstrate efficacy. J Hosp Infect. 2015;91:319-25.
4. Center for Disease Control. 2017 National and state healthcare-associated infections progress report. CDC. 2017. https://www.cdc.gov/HAls/data/ archive/2017-HAIS-progressreport.html. Accessed 27 Feb 2020

5. Navalkele BD, Bezlotoxumab CT. An emerging monoclonal antibody therapy for prevention of recurrent Clostridium difficile infection. Biol Targets Ther. 2018;12:11-21.

6. Center for Disease Control. Biggest threats and data. CDC. 2019. https:// www.cdc.gov/drugresistance/biggest-threats.html\#cdiff. Accessed 27 Feb 2020.

7. Kyne L, Hamel MB, Polavaram R, Kelly CP. Health care costs and mortality associated with nosocomial diarrhea due to Clostridium difficile. Clin Infect Dis. 2002;34:346-53.

8. Boyce JM. Environmental contamination makes an important contribution to hospital infection. J Hosp Infect. 2007:65:50-4.

9. Eckstein BC, Adams DA, Eckstein EC, Rao A, Sethi AK, Yadavalli GK, Donskey CJ. Reduction of Clostridium difficile and vancomycin-resistant Enterococcus contamination of environmental surfaces after an intervention to improve cleaning methods. BMC Infect Diseases. 2007;7:61-6.

10. Guerrero DM, Nerandzic MM, Jury LA, Jinno S, Chang S, Donskey CJ. Acquisition of spores on gloved hands after contact with the skin of patients with Clostridium difficile infection and with environmental surfaces in their rooms. Am J Infect Control. 2012;40:556-8.

11. Shams AM, Rose $L$, Edwards JR, Cali S, Harris AD, Jacob JT, LaFae A, Pineles LL, Thom KA, McDonald LC, Arduino MJ. Assessment of the overall and multidrug-resistant organism bioburden on environmental surfaces in healthcare facilities. Infect Control Hosp Epidemiol. 2016;37:1426-32.

12. Rashid T, Haghighi F, Hasan I, Bassères E, Alam MJ, Sharma SV, Lai D, DuPont HL, Garey KW. Activity of hospital disinfectants against vegetative cells and spores of Clostridioides difficile embedded in biofilms. Antimicrob Agents Chemother. 2019. https://doi.org/10.2147/BTT.S127099.

13. Kramer A, Schwebke I, Kampf G. How long do nosocomial pathogens persist on inanimate surfaces? A systematic review. BMC Infect Dis. 2006:6:130-7.

14. Fawley WN, Underwood S, Freeman J, Baines SD, Saxton K, Stephenson $\mathrm{K}$, Owens RC, Wilcox MH. Efficacy of hospital cleaning agents and germicides against epidemic Clostridium difficile strains. Infect Control Hosp Epidemiol. 2007;28:920-5

15. Yokoe DS, Anderson DJ, Berenholtz SM, Calfee DP, Dubberke ER, Eilingson KD, Gerding DN, Haas JP, Kaye KS, Klompas M, Lo E. A compendium of strategies to prevent healthcare-associated infections in acute care hospitals: 2014 updates. Infect Control Hosp Epidemiol. 2014;35:21-31.

16. Wiemken TL, Curran DR, Pacholski EB, Kelley RR, Abdelfattah RR, Carrico RM, Ramirez JA. The value of ready-to-use disinfectant wipes: compliance, employee time, and costs. Am J Infect Control. 2014;42:329-30.

17. Ferreira AM, Andrade DD, Rigotti MA, Almeida MT, Guerra OG, Santos Junior AG. Assessment of disinfection of hospital surfaces using different monitoring methods. Rev Lat Am Enferm. 2015:23:466-74.

18. Wagers KJ, SC Johnson, Son Inventor Inc, assignee. All purpose cleaner with low organic solvent content. United States patent US 6,384,010. 2002

19. Mitra S, Simon RE, Scott WB, Vieira K, Shaffer GA, inventors; Clorox Co, assignee. Bactericidal cleaning wipe. United States patent US 6,673,761. 2004

20. Napolitano LA, Monticello MV, Blank R, Odame G, inventors; Professional Disposables International Inc, assignee. Quaternary ammonium glycol ether disinfectant wipes. United States patent application US 12/849,577. 2012.

21. Sattar SA, Bradley C, Kibbee R, Westgate R, Wilkinson MAC, Sharpe T, Maillard JY. Disinfectant wipes are appropriate to control microbial bioburden from surfaces: use of a new ASTM standard test protocol to demonstrate efficacy. J Infect Control. 2015;91:319-25

22. Lineback CB, Nkemngong CA, Wu ST, Li X, Teska PJ, Oliver HF. Hydrogen peroxide and sodium hypochlorite disinfectants are more effective against Staphylococcus aureus and Pseudomonas aeruginosa biofilms than quaternary ammonium compounds. Antimicrob Resist Infect Control. 2018;7:154. https://doi.org/10.1186/s13756-018-0447-5.

23. Nobile CG, Montuori P, Diaco E, Villari P. Healthcare personnel and hand decontamination in intensive care units: knowledge, attitudes, and behaviour in Italy. J Hosp infect. 2002;51:226-32.

24. Shrestha SK, Sunkesula VC, Kundrapu S, Tomas ME, Nerandzic MM, Donskey CJ. Acquisition of Clostridium difficile on hands of healthcare 
personnel caring for patients with resolved C. difficile infection. Infect control Hosp Epidemiol. 2016;37:475-7.

25. Chowdhury D, Rahman A, Hu H, Jensen SO, Deva AK, Vickery K. Effect of disinfectant formulation and organic soil on the efficacy of oxidizing disinfectants against biofilms. J Hosp Infect. 2019;103:33-41.

26. Becker B, Henningsen L, Paulmann D, Bischoff B, Todt D, Steinmann E, Steinmann J, Brill FH, Steinmann J. Evaluation of the viricidal efficacy of disinfectant wipes with a test method simulating practical conditions. Antimicrob Resist Infect Control. 2019:8:121.

27. Environmental Protection Agency. Procedure for the OECD quantitative method for testing antimicrobial products against spores of Clostridium difficile (ATCC 43598) on inanimate, hard, non-porous surfaces. EPA 2017. https://www.epa.gov/sites/production/files/2017-09/documents/mb31-final.pdf. Accessed 27 Feb 2020.

28. Environmental Protection Agency. EPA MLB SOP-MB-31: Procedure for the OECD Quantitative Method for Testing Antimicrobial Products against Spores of Clostridium difficile (ATCC 43598) on Inanimate, Hard, Non-porous Surfaces. EPA 2017. https://www.epa.gov/sites/production/ files/2017-12/documents/mb-31_december_2017.pdf. Accessed 15 Oct 2020

29. Environmental Protection Agency. EPA MLB SOP MB-28: Procedure for the Production and Storage of Spores of Clostridium difficile for Use in the Efficacy Evaluation of Antimicrobial Agents. EPA 2017. https://www.epa. gov/sites/production/files/2017-12/documents/mb-28_december_2017. pdf. Accessed 15 Oct 2020.

30. Center for Disease Control. Biggest threats and data. CDC. 2010. https ://www.cdc.gov/HAls/pdfs/sir/national-SIR-Report_03_29_2012.pdf. Accessed 27 Feb 2020.

31. Lopez GU, Kitajima M, Havas A, Gerba CP, Reynolds KA. Evaluation of a disinfectant wipe intervention on fomite-to-finger microbial transfer. Appl Environ Microbiol. 2014:80:3113-8.

32. West AM, Nkemngong CA, Voorn MG, Wu T, Li X, Teska PJ, Oliver HF. Surface area wiped, product type, and target strain impact bactericidal efficacy of ready-to-use disinfectant Towelettes. Antimicrob Resist Infect Control. 2018;7:122.

33. Samore MH, Venkataraman L, DeGirolami PC, Arbeit RD, Karchmer AW. Clinical and molecular epidemiology of sporadic and clustered cases of nosocomial Clostridium difficile diarrhea. Am J Med. 1996;100:32-40.

34. Mayfield JL, Leet T, Miller J, Mundy LM. Environmental control to reduce transmission of Clostridium difficile. Clin Infect Dis. 2000;31:995-1000.

35. Gingras G, Guertin MH, Laprise JF, Drolet M, Brisson M. Mathematical modeling of the transmission dynamics of Clostridium difficile infection and colonization in healthcare settings: a systematic review. PLOS ONE. 2016. https://doi.org/10.1371/journal.pone.0163880.
36. Cardoso CF, Faria JAF, Walter EHM. Modeling of sporicidal effect of hydrogen peroxide in the sterilization of low density polyethylene film inoculated with Bacillus subtilis spores. Food Control. 2011;22:1559-64.

37. Center for Disease Control. Disinfection and Sterilization. CDC. 2018. https //www.cdc.gov/infectioncontrol/guidelines/disinfection/index.html. Accessed 27 Feb 2020.

38. Gonzalez EA, Nandy P, Lucas AD, Hitchins VM. Ability of cleaning-disinfecting wipes to remove bacteria from medical device surfaces. Am J Infect Control. 2015:43:1331-5.

39. Kenters N, Huijskens EG, de Wit SC, Sanders IG, van Rosmalen J, Kuijper EJ, Voss A. Effectiveness of various cleaning and disinfectant products on Clostridium difficile spores of PCR ribotypes 010,014 and 027. Antimicrob Resist Infect Control. 2017;6:54.

40. Gold KM, Hitchins VM. Cleaning assessment of disinfectant cleaning wipes on an external surface of a medical device contaminated with artificial blood or Streptococcus pneumoniae. Am J Infect Control. 2013;41:901-7.

41. Masuku SM, Babu D, Martin EM, Koo OK, O'Bryan CA, Crandall PG, Ricke SC. Cleaning and decontamination efficacy of wiping cloths and silver dihydrogen citrate on food contact surfaces. J Appl Microbiol. 2012;113:89-95.

42. Center for Disease Control. Guideline for disinfection and sterilization in healthcare facilities. CDC. 2008. https://www.cdc.gov/infectioncontrol/ guidelines/disinfection/efficacy.html. Accessed 27 Feb 2020.

43. Rutala WA, Gergen MF, Weber DJ. Efficacy of different cleaning and disinfection methods against Clostridium difficile spores: importance of physical removal versus sporicidal inactivation. Infect Control Hosp Epidemiol. 2012;33:1255-8.

44. Environmental Protection Agency. Methods and guidance for testing the efficacy of antimicrobial products against spores of Clostridium difficile on hard non-porous surfaces. EPA 2019.https://www.epa.gov/pesticide-regis tration/methods-and-guidance-testing-efficacy-antimicrobial-productsagainst-spores\#products. Accessed 27 Feb 2020.

\section{Publisher's Note}

Springer Nature remains neutral with regard to jurisdictional claims in published maps and institutional affiliations.
Ready to submit your research? Choose BMC and benefit from:

- fast, convenient online submission

- thorough peer review by experienced researchers in your field

- rapid publication on acceptance

- support for research data, including large and complex data types

- gold Open Access which fosters wider collaboration and increased citations

- maximum visibility for your research: over $100 \mathrm{M}$ website views per year

At BMC, research is always in progress.

Learn more biomedcentral.com/submissions 